\title{
El funcionamiento económico de una institución supramunicipal clave en la gestión del agua en la Comunidad Valenciana: El Consorcio de Aguas de la Marina Baja (Alicante)
}

\author{
Teresa Torregrosa y \\ Martín Sevilla \\ Departamento de Análisis Económico Aplicado \\ Universidad de Alicante
}

\begin{abstract}
Sumario: I. INTRODUCCIÓN.-II. LA IMPORTANCIA DE LAS INSTITUCIONES EN LA GESTIÓN DE LOS RECURSOS HÍDRICOS. LA ECONOMÍA COMO ACTIVIDAD INSTITUCIONALIZADA.-III. LA GESTIÓN DEL AGUA EN LA COMARCA DE LA MARINA BAJA, ALICANTE. EL CONSORCIO DE AGUAS DE LA MARINA BAJA. 3.1. La gestión del agua mediante Consorcios en España. 3.2. El Consorcio de Aguas de la Marina Baja (CAMB).-IV. FUNCIONAMIENTO ECONÓMICO-PRESUPUESTARIO DEL CAMB.-V. CONCLUSIONES.
\end{abstract}

Resumen: La economía es una actividad institucionalizada y de ahí la importancia de identificar y analizar las instituciones implicadas en cada fenómeno económico. En la gestión de los recursos hídricos la importancia de los aspectos institucionales ha quedado patente en la reciente historia económica española. En muchas ocasiones, el éxito o fracaso de un modelo de gestión de los recursos hídricos depende, en gran medida, de las instituciones encargadas y básicamente aquellas situadas en la escala más desagregada posible.

Con este trabajo se trata de analizar las razones del surgimiento de una institución que, en la actualidad, es clave en la gestión del suministro de agua en una zona donde la articulación de los usos agrarios, urbanos y turísticos -no olvidemos que en la misma se ubica el municipio de Benidorm-, ha permitido mejorar la eficiencia del sistema como un todo. Por otro lado, esta investigación también aporta claves sobre el funcionamiento económico de los Consorcios Administrativos, figura administrativa a la que se ha prestado poca atención desde el punto de vista económico y que con este trabajo se aportan elementos para su análisis.

Palabras clave: Instituciones, Consorcio de Aguas de la Marina Baja, compensaciones, gastos fijos y variables, recursos hídricos. 


\section{JEL Classification: D02, Q25, R51}

«Sin instituciones apropiadas, las políticas no funcionarán; sin políticas apropiadas, las instituciones no funcionarán» (Global Water Partnership Toolbox, GWPT).

\section{INTRODUCCIÓN}

En un tema como la gestión de los recursos hídricos no sólo es importante saber con qué recursos se cuenta a la hora de gestionar, sino quiénes van a ser los encargados de dicha gestión y en qué forma están coordinados para dar respuesta a las diversas situaciones que se plantean.

Tanto el establecimiento de un marco legal adecuado como la implementación de políticas apropiadas son, en esencia, funciones que deben emanar de administraciones responsables. De ahí la importancia de un buen entramado institucional, coordinado y competente, que garantice un funcionamiento integrado también en las instituciones responsables de la gestión del agua. La descentralización política viene siendo un proceso destacable en este ámbito desde la aprobación del conocido Informe Bruntdland en 1989. El «principio de sector responsable» (Hovik y Reitan, 2004, p.691) establecía que todos los niveles de gobierno deberían llevar a cabo políticas de desarrollo sostenible en sus respectivos dominios y por supuesto de manera coordinada. Sin embargo, la variedad de instituciones implicadas en la gestión del agua es tan amplia y éstas tan numerosas, que intentar identificarlas todas para una zona concreta, tanto si su influencia es directa o indirecta, es una tarea complicada.

En un trabajo más amplio (Torregrosa, 2008), hemos identificado hasta treinta y tres instituciones que, directa o indirectamente afectan a la gestión de los recursos hídricos en la comarca de la Marina Baja. De entre todas ellas destaca, por la importancia del papel jugado en el mantenimiento del equilibrio en lo que a gestión de recursos hídricos se refiere, el Consorcio de Aguas de la Marina Baja, (en adelante CAMB) figura de ámbito supramunicipal encargada del diseño de la política de gestión de los recursos hídricos en la Marina Baja (Alicante). Una visión de los consorcios de aguas existentes en España y en la Provincia de Alicante en concreto, permite comprobar el éxito de este tipo de instituciones en la gestión del agua a nivel local o supramunicipal. El análisis económico-presupuestario y su interrelación con los agentes implicados definen el trabajo que aquí presentamos, poniendo de manifiesto las ventajas, inconvenientes y particularidades de este tipo de instituciones.

\section{LA IMPORTANCIA DE LAS INSTITUCIONES EN LA GESTIÓN DE LOS RECURSOS HÍDRICOS. LA ECONOMÍA COMO ACTIVIDAD INSTITUCIONALIZADA}

La definición de institución puede tener diversas interpretaciones, siendo éstas, a

104 veces, incluso contradictorias. Algunos autores (Bromley, 1989; North, 1993; Ostrom, 
2000) han definido las instituciones del agua como «reglas que conjuntamente describen situaciones, delinean escenarios de acción, proveen incentivos y determinan consecuencias tanto para las decisiones individuales como colectivas relacionadas con el desarrollo, asignación, uso y gestión de los recursos hídricos» (Castro et al., 2006, p. 31). En el sector del agua las instituciones desarrollan actividades en ámbitos muy diferentes. La función principal es facilitar la gestión del agua reduciendo los costes de implementación y fomentando una asignación eficiente, equitativa y sostenible de recursos (Johansson, 2000). La consideración del agua como bien económico en todas sus dimensiones, tal y como reza el tercero de los Principios de Dublín, tanto por agencias gubernamentales como por empresas de servicios pasando por organismos de cuenca, viene a fortalecer la capacidad de asignación eficiente de los recursos por parte de las instituciones, incrementando la confianza en las fuerzas de mercado, asegurando la autosuficiencia financiera y promoviendo estructuras de decisión descentralizadas a través de tecnologías avanzadas e información (Saleth y Dinar, 1999, p. viii). Estos preceptos están muy en consonancia con las bases de una gestión integrada de recursos (Torregrosa et al., 2006).

El antagonismo tradicional existente entre el libre mercado y la intervención estatal ha sido matizado por algunos autores. Aguilera-Klink y Sánchez-García (2005, pp. 167-168) afirman que «el mercado es un sistema institucionalizado de intercambios que funciona bajo unas reglas de juego específicas que pueden ser establecidas por el gobierno o por el parlamento». En la misma línea, Polany, (1976) argumentaba también que, independientemente de la definición que otorgásemos a la economía, ésta es una actividad institucionalizada. Por tanto,» [... ] las actividades económicas están insertadas en un contexto social y cultural que tiene lugar bajo una estructura institucional continuamente en evolución a la que llamamos reglas, legislación, acuerdos o regulaciones colectivas que establecen normas aceptables a nivel individual o de grupo»(Aguilera-Klink y Sánchez-García, 2005, p. 170). De esta manera, los problemas económicos, en muchas ocasiones asociados tanto al mercado como a la intervención pública, pueden ser considerados como ejemplos de conflicto y debilidad u obsolescencia en el funcionamiento de las instituciones económicas. Mishan (1967) por su parte, confiere una gran importancia al marco institucional en el que las actividades de mercado se desempeñan. Frente a la idea, equivocada según el autor, de que los problemas relacionados con el medio ambiente -las externalidades, sobre todo- son el resultado del funcionamiento propio del mercado, Mishan opina, al igual que Polany, que se deben a las insuficiencias que presenta el marco institucional en el cual el mercado opera, y que una posible solución pasa por la modificación de las instituciones implicadas.

La importancia de las instituciones en la actividad económica en general, y en el sector que nos ocupa en este caso, el sector del agua, queda suficientemente justificada, a nuestro entender, en los trabajos de los autores antes citados. En España, son numerosas las instituciones que intervienen, de manera directa o indirecta, en la gestión del agua, y por tanto, numerosos también los problemas asociados. Entre ellos, la pasividad y la falta de control por parte de las administraciones con competencias en la materia, son dos de los más destacados (Torregrosa et al., 2006). La fragmentación de competencias es muy elevada, lo que implica, en palabras de García-Serra y 
Cabrera (1998) «que muchos tengan derecho a opinar, e incluso a decidir, pero que nadie sea, finalmente, responsable de nada».

En tanto que los Principios de Dublín subrayan el hecho de que las decisiones deben tomarse siempre al nivel más bajo que sea apropiado, es esencial reconocer que ese nivel puede variar mucho de un caso a otro -en el caso de cuencas fluviales transfronterizas, la escala de gestión más apropiada para muchas de las decisiones tendría que ser la internacional-. Todo lo anterior resalta la importancia de crear vínculos entre las distintas escalas a través de la integración vertical, con el fin de asegurar unos resultados duraderos. La Directiva Europea Marco del Agua (en adelante, DMA) apuesta por los organismos de cuenca como instrumento clave desde el punto de vista institucional que hace de la gestión en el ámbito de la cuenca un foro ideal para la coordinación, la participación de la comunidad, la resolución de conflictos y la evaluación de los recursos. Desde muchos ámbitos de nuestra sociedad y como consecuencia del proceso de implementación de la DMA cobra cada vez más fuerza la idea de un necesario cambio en el sistema institucional encargado de la gestión del agua en nuestro país.

La gestión de los recursos hídricos a escala local o supralocal propicia la existencia de una elevada participación e implicación de los individuos en la gestión de los recursos, con el conocimiento previo de unas reglas de funcionamiento sabidas y respetadas por todos, no siempre escritas, acordes a las condiciones locales. Sin embargo, el excesivo interés por la participación de todos los individuos involucrados o afectados por las políticas de gestión del agua, ha llevado al retraso en la aplicación de muchas de las medidas y a la disolución del objetivo inicial. La participación en la gestión o el grado de afección de los actores involucrados es tan variado y tan amplio, que pretender la participación de todos ellos es tarea complicada, cuando no poco efectiva. Los sistemas democráticos se mueven en base a procedimientos de representación, no a la participación directa de los afectados.

\section{LA GESTIÓN DEL AGUA EN LA COMARCA DE LA MARINA BAJA, ALICANTE. EL CONSORCIO DE AGUAS DE LA MARINA BAJA}

Tanto los consorcios como las mancomunidades se han revelado como instrumentos muy útiles para la gestión común de servicios asignados generalmente a las administraciones locales y que en buena parte de los municipios de menor tamaño y recursos financieros escasos resultarían difíciles de desarrollar por sí mismos. Si bien los consorcios han tenido tradicionalmente un desafortunado tratamiento legal según palabras de Martín Mateo (1992, p. 7), los mismos toman plena carta de naturaleza en el Régimen Local. Tanto la Ley Reguladora de Bases del Régimen Local como su texto refundido ${ }^{1}$ establecen en su articulo 110 que «las Entidades pueden constituir consor-

1 Ley 7/1985, de 2 de abril, Reguladora de las Bases del Régimen Local y Real Decreto Legislativo 781/1986, de 18 de abril, por el que se aprueba el Texto Refundido de las Disposiciones Legales vigentes en materia de Régimen Local respectivamente 
cios con otras Administraciones Públicas para fines de interés común o con entidades privadas sin ánimo de lucro que persigan fines de interés público concurrentes con los de las Administraciones Públicas» añadiendo que los consorcios gozarán de personalidad jurídica propia. El último informe del IGAE (2008) sobre el Sector Público Empresarial recoge que el Consorcio es una figura mediante la que se puede instrumentar la colaboración entre distintas Administraciones públicas, con o sin la participación de particulares. Los denominados Consorcios públicos resultan de la agrupación de entidades públicas de diferente orden para la gestión de los servicios y siguen el régimen jurídico que las Administraciones Consorciadas establezcan en el convenio, de acuerdo con la normativa que a ellas es aplicable. Son tres los ámbitos en donde pueden calificarse los consorcios; el ámbito estatal, la Ley General Presupuestaria² los define en su artículo 2.1h) estableciendo la exigencia tanto de dominio financiero como de dominio político para que un Consorcio tenga la consideración de Sector Público Estatal; en el ámbito autonómico, no existe uniformidad en la regulación de esta figura por parte de las distintas Leyes de Organización y Gobierno o de Hacienda y Finanzas de las Comunidades Autónomas, coincidiendo algunas con la definición estatal; en el ámbito local, como ya se ha mencionado, es la Ley 7/1985, Reguladora de Bases de Régimen Local la que fija su creación y funcionamiento.

Si atendemos al inventario elaborado por el IGAE (2008) se observa como la proliferación y la distinta naturaleza de los consorcios creados -si figuran asociados Diputaciones Provinciales y distintos Ayuntamientos, si se asocian con la Administración Central, etc.- permite realizar solo una aproximación a su cifra real, siendo de todas formas, un catálogo bastante completo. De los 752 consorcios según el inventario de 31 de diciembre de 2005, se ha pasado a 920 consorcios un año después, siendo muy mayoritarios los consorcios de ámbito local, unos 910. Lo interesante es destacar la naturaleza del caso que nos ocupa, el CAMB. Este se adscribe a los clasificados como «Entidad participada por el Sector Público Provincial -Diputación Provincial de Alicante-, Sector Público Municipal -Ayuntamientos de la Comarca- y Sector Público Estatal- Confederación Hidrográfica del Júcar»³.

Aún así, el CAMB se adscribe al ámbito local por ser ésta la administración con participación mayoritaria, con un $83,88 \%$ frente al 9,67\% del Estado y el 6,45\% de la Diputación Provincial de Alicante (IGAE, 2008, p. 858).

El motivo de porqué esta figura y no otra, fue una razón práctica. El municipio de Benidorm sugirió en 1973 la creación de una Mancomunidad en lugar del Consorcio ${ }^{4}$ alegando que era más adecuada ante la situación de la comarca de atender otros servicios como el de recogida de basuras, extinción de incendios, etc. añadiendo ade-

2 Ley 47/2003, de 26 de noviembre, General Presupuestaria.

3 A diferencia de lo que ocurre con otro de los consorcios cercanos, el Consorcio de Servicio de Abastecimiento y Saneamiento de Aguas de la Marina Alta, que se incluiría en aquellos consorcios donde figuran una comunidad autónoma y otras administraciones locales, esto es, la Generalitat Valenciana, Diputación de Alicante y distintos Ayuntamientos.

4 Acta de 15 de junio de 1973 de la Comisión Gestora del Consorcio de Aguas de la Marina Baja. 
más que la constitución del consorcio con representantes de la Diputación y de la Confederación Hidrográfica del Júcar haría más lentas y difíciles las reuniones. La réplica vino por parte del entonces Jefe Provincial del Servicio de Inspección y Asesoramiento, Patricio Saura, en donde advirtió que al incluir a la Confederación y la Diputación se agilizaría la tramitación de expedientes y obras que por su naturaleza requiriesen su intervención. Además, la presidencia de estas dos administraciones aportaría al Consorcio un prestigio de entidad que difícilmente podría tener de otro modo. Concluyó diciendo lo siguiente: «La solución legal, formando parte las entidades de la Diputación y la Confederación Hidrográfica del Júcar, es la de Consorcio, porque así se establece en el reglamento de servicio, y aunque figura relativamente nueva, ya tiene bastantes manifestaciones en nuestra Patria, que nos han servido de enseñanza y de la que conocemos su viabilidad».

Pese a que son numerosos los servicios en base a cuya prestación se constituyen los consorcios -protección y preservación del medio ambiente, promociones de actividades turísticas, infraestructuras deportivas, etc.-, el tratamiento de residuos sólidos urbanos y el abastecimiento de aguas son los objetivos esenciales de la mayoría de los creados.

Nuestro interés se centra en los consorcios de abastecimiento de aguas, abordados por la Ley de Aguas de 1985 y su consiguiente texto refundido. El artículo 89 del Texto Refundido de la Ley de Aguas (en adelante, TRLA) señala que «1. El otorgamiento de las concesiones para abastecimiento a varias poblaciones estará condicionado a que las Corporaciones Locales estén constituidas a estos efectos en Mancomunidades, Consorcios u otras entidades semejantes, de acuerdo con la legislación por la que se rijan, o a que todas ellas reciban el agua a través de una misma empresa concesionaria». En nuestro caso particular, El Consorcio de Abastecimiento y Saneamiento de la Comarca de la Marina Baja, el CAMB, pertenece además al subgrupo de consorcios con presencia estatal dada la participación de la Confederación Hidrográfica del Júcar como miembro de pleno derecho. A este respecto, Sosa Wagner (2008, p. 374) expresa sus reservas a los consorcios con participación estatal ya que si existen normas de aquel origen serán las directamente aplicables. Sin embargo, el ordenamiento estatal ya se ha pronunciado al respecto al incluir, sin matizaciones, a los Consorcios en el Régimen Local (Martín Mateo, 1992, p. 13). Siguiendo a Martín Mateo (Ibíd., p. 15), la participación no necesariamente se justifica por razones ideológicas, sino que constituye, más bien, un prerrequisito técnico para la operabilidad de los criterios del bien común. Lo mismo puede decirse de la distribución espacial de cometidos, hay pocas intervenciones que quepan holgadamente en los reductos de una demarcación territorial determinada, sea esta un municipio o el propio Estado.

Una cuestión interesante que no debemos pasar por alto es la falta de presencia de la Administración Autonómica entre los entes consorciados en el CAMB. Una administración como la Generalitat Valenciana, con una importante presencia en lo que a construcción de infraestructuras se refiere -obras de canalización, desaladoras, es108 taciones depuradoras, etc.- y otros asuntos no menos relevantes, no figura entre los 
participantes en el Consorcio. El motivo lo encontramos en los Estatutos del CAMB, aprobados éstos en 1977, y por tanto, previos al Estado de las Autonomías. La reticencia a modificarlos desde entonces, pese a algunos intentos frustrados, explica porqué mientras que las necesidades se han mantenido a lo largo de los años, la organización del ente no se ha adaptado a los nuevos tiempos. El ejemplo más claro lo tenemos en el Consorcio de Aguas de la Marina Alta, que, creado en 1987, sí recoge a la Generalitat Valenciana entre sus consorciados clasificándose por tanto, según el inventario del IGAE (2008, p. 703), entre las entidades participadas por el Sector Público Autonómico y el Sector Público Provincial y/o Municipal.

\subsection{La gestión del agua mediante Consorcios en España}

Ya hemos comentado que el CAMB no es la única organización de este tipo en España, ni siquiera en la Provincia de Alicante, ya que se contabilizan, además del CAMB, consorcios como el de Aguas de la Marina Alta desde 1987 y el Consorcio de Aguas de Teulada-Benitatxell5, aunque su funcionamiento es más bien irregular.

En el resto de España, el Ministerio de Obras Públicas (MOP) a través de la Confederación Hidrográfica del Norte, y la Diputación Provincial de Oviedo, realizaron una serie de estudios encaminados a resolver los graves problemas de abastecimiento de agua que se planteaban en la Comarca Central de Asturias. En 1967 el MOP procedió a la autorización de los Estatutos del Consorcio para el Abastecimiento de la Zona Central de Asturias.

Lo mismo ocurrió en Vizcaya donde el 17 de Marzo de 1967 se creó el Consorcio para el Abastecimiento de Agua y Saneamiento de la Comarca del Gran Bilbao con 19 municipios. En 1997 tras la adaptación estatutaria a la Norma Foral 3/95, de 30 de Marzo, reguladora de las Entidades de Ámbito Supramunicipal de Bizkaia y demás normativa de Régimen Local, el Consorcio cambió su denominación a Consorcio de Aguas Bilbao Bizkaia, abasteciendo a 63 municipios y a una población de 1.000.000 de habitantes.

También impulsado por la Diputación Provincial nació en 1992 el Consorcio de Aguas de Guipúzcoa que agrupa a 68 municipios y 350.000 ciudadanos $^{6}$. El Consorcio de la Costa Brava se creó en 1971 integrado por la Diputación de Girona y los 27 municipios del litoral gironí. Desde 1993 el Consorcio de la Costa Brava ha pasado a ser organismo actuante de la Agencia Catalana del Agua. Las similitudes entre este consorcio y el CAMB radican fundamentalmente en la necesidad de abastecer a una población creciente a causa de su actividad económica principal, el turismo ${ }^{7}$. Algunos años des-

5 BOP 31/03/1987 y BOP 9/11/1988 respectivamente.

6 Aunque en el País Vasco son muchos los Consorcios registrados, hasta 14 diferentes, hemos mencionado el de Bilbao y el de Guipúzcoa como dos de los más relevantes, siendo el Consorcio uno de los entes gestores en cuanto a abastecimiento y saneamiento de aguas más destacados en la zona, con un 93,4\% de la población servida. Véase Eraso, 2006.

7 Consorcio de Aguas de la Costa Brava, http://www.ccbgi.org. 
pués, en 1985, se constituye el Consorcio de Aguas de Tarragona-CAT-, cuya creación vino condicionada por la aprobación de la Ley 18/1981 de 1 de julio sobre actuaciones en materia de aguas en Tarragona ${ }^{8}$, que requería la creación de un ente que habría de resultar concesionario optando por la forma de un consorcio. En julio de 1982 se constituyó una Comisión Gestora al igual que ocurriese con el CAMB, integrada por los representantes de la Administración de la Generalitat, de los Ayuntamientos e industrias interesadas -en sus inicios formaban parte del CAT 21 municipios y 18 industrias; en el año 2006 son 70 los municipios y 34 las industrias consorciadas- y de las dos Comunidades de Regantes que habían de ceder los caudales ${ }^{9}$, Comunidad General de Regantes del Canal de la Derecha del Ebro y Comunidad de Regantes Sindicato Agrícola del Ebro, Margen Izquierda. Finalmente el CAT se formalizó en escritura pública el 2 de abril de 1985, entrando a formar parte con la condición de miembro de cada una de las dos comunidades de regantes -de acuerdo con la modificación de los estatutos y ordenanzas de cada una de ellas, el 02.10.1988 en la Comunidad de Regantes Margen Izquierda y 02.07.1990 Comunidad de Regantes Margen Derecha, y éstas como miembros a su vez del CAT (Erruz, 1997).

En la Costa del Sol, Málaga, opera otro organismo similar pero con una forma jurídica diferente a la del CAMB. ACOSOL, es una empresa pública propiedad de la Mancomunidad de Municipios de la Costa del Sol Occidental, que además de prestar los servicios de abastecimiento y saneamiento de agua se encarga, dada la naturaleza de Mancomunidad, de la provisión de otros servicios como la recogida de residuos sólidos urbanos. Algo parecido ocurre en Lanzarote con la empresa Insular de Aguas de Lanzarote S.A. (INALSA), que se constituyó el 19 de agosto de 1989 para la gestión de los recursos y objetivos contemplados en los Estatutos del Consorcio Insular de Aguas de Lanzarote, su único accionista que a su vez está participando en un $60 \%$ por el Cabildo Insular de Lanzarote y en un $40 \%$ por los 7 ayuntamientos de la Isla. También en la Comunidad Canaria tenemos el Consorcio de Abastecimiento de Aguas de Fuerteventura.

Aunque son muchos los que quedan por mencionar ${ }^{10}$, queden estos como ejemplo de los más destacados, relevantes en las zonas en las que operan, por sus similitudes con el CAMB o por sus disparidades.

8 BOE 11/07/1981.

9 Este último aspecto es relevante, ya que si bien es cierto que en algunas reuniones del CAMB se planteó la participación de alguna manera de los usuarios agrícolas, las dificultades que suponía su integración a un organismo plenamente en funcionamiento -modificación de estatutos incluida, considerando que los Estatutos del CAMB llevan sin modificarse desde su aprobación en 1977 pese a los intentos y los borradores que se han ido elaborando. La falta de acuerdo ha impedido que hasta el día de hoy se modifiquen-, y la decisión de qué usuarios o representantes participaban y cuáles no, llevó a la decisión de contar con ellos cuando se estimase necesario sin aceptar su inclusión como miembros de pleno derecho del CAMB, ni siquiera en cuando a asistencia a los plenos como inicialmente se planteó. Acta de la Sesión Extraordinaria de 30 de octubre de 1995 , punto $2 .^{\circ}$.

10 Un estudio publicado en 2005 en el boletín de la AGE establece en 201 las iniciativas bajo la fórmula de consorcios registrados en España. De esas 201, una parte muy significativa se centra en Cataluña con 82 y 


\subsection{El Consorcio de Aguas de la Marina Baja (CAMB)}

La comarca de la Marina Baja, en el sureste peninsular, representa unas particularidades físicas, económicas y sociales que la convierten en el escenario idóneo para el análisis de prácticas de utilización conjunta de recursos y de la importancia de existencia de una institución de carácter supra-local como un consorcio de aguas. El carácter temporal de la disponibilidad de recursos, la peculiaridad de las demandas agrícolas y urbano-turísticas con el municipio de Benidorm a la cabeza, la competencia entre usuarios por los recursos disponibles de distinta procedencia y la dicotomía costa-interior, tanto en su vertiente física como en la económica, son algunas de las características distintivas que apuestan por la gestión integrada de recursos, desarroIlada principalmente por el Consorcio para Abastecimiento de Aguas y Saneamientos de la Marina Baja.

La Comisión Gestora del CAMB se constituyó en mayo de 1972, al amparo de la política hídrica de la época, que pasaba entonces por la elaboración del Plan Nacional de Abastecimiento y Saneamiento. En base a este Plan Nacional, y bajo el amparo del II Plan de Desarrollo Económico y Social, se establecieron una serie de «Medidas para aumentar la productividad de los diferentes sectores y fomentar las inversiones» (Presidencia del Gobierno, 1967b). Dentro del sector de abastecimientos, agua y saneamientos se plantean dos medidas esenciales: una política de tarifas para lograr que esos servicios sean autofinanciables, y otra muy relevante para el caso que nos ocupa, como es «el fomento de las mancomunidades y consorcios de municipios para obras y explotación de abastecimientos en común». Y es a partir de esta medida, desde donde surgen la mayor parte de las iniciativas de consorcios de aguas en España, y entre ellas, el $\mathrm{CAMB}$, una entidad jurídica pública local en aquellos momentos, de carácter asociativo e institucional, según reza en sus estatutos, y siendo dotada de capacidad jurídica de derecho público y privado es «tan amplia como lo requiera la realización de sus fines».

El Ministerio de Obras Públicas, siguiendo las directrices del II Plan de Desarrollo Económico y Social y la medida de fomento de mancomunidades y consorcios que acabamos de comentar, propició la celebración de varias reuniones en 1967 entre el Gobierno Civil, la Diputación Provincial de Alicante y los municipios más afectados de la comarca por la situación de sequía, proponiendo la creación de un consorcio de aguas. El 12 de Marzo de 1968, teniendo como base un anteproyecto suscrito por Emilio Felter López, ingeniero de la Confederación Hidrográfica del Júcar¹1, (en ade-

11 Este anteproyecto fue publicado en el BOP en marzo de 1968, habiendo sido suscrito por el ingeniero Emilio Felter con fecha 11 de diciembre de 1967 y aprobado técnicamente por resolución de la Dirección General de Obras Hidráulicas el 7 de marzo de 1968 al amparo del Plan Nacional de Abastecimiento y Saneamiento. A finales del verano de 1969, ante la gravedad de la situación de abastecimiento en Benidorm, se confecciona en dicho ayuntamiento una memoria con la situación y las posibles soluciones, haciéndolo llegar a la DGOH. Todas estas iniciativas se plasman en un documento que se publica finalmente en el BOE n. 251 , de 20 de octubre de 1969, haciendo referencia a la construcción de obras de abastecimiento para las poblaciones de Altea, Alfaz del Pí, Benidorm, Finestrat, Villajoyosa, Polop, la Nucía y Callosa d’En Sarriá. (Acta del 23/05/1967 CAMB y Diario INFORMACION, 21/10/1969, p. 13). 
lante, $\mathrm{CHJ}$ ), se firmó en el Ayuntamiento de Benidorm, bajo la presidencia del Ministro de Obras Públicas, Federico Silva Muñoz, un acta que «solemniza la decisión de constituir un consorcio voluntario, para las localidades de Altea, Alfaz del Pí, Benidorm, Benisa, Benitachell, Calpe, Gata de Gorgos, Jávea y Teulada»².

Sin embargo, el planteamiento inicial de municipios consorciados se modifica ante la negativa de algunas localidades como Benidorm, Altea, Villajoyosa y La Nucía, que expresaron su oposición a los socios inicialmente planteados alegando razones geográficas más razonables. En opinión de estos municipios, se debería constituir un consorcio incluyendo sólo a aquellos municipios que por razón de proximidad a la zona de donde se captan las aguas -esto es, la zona del río Algar- favoreciesen un funcionamiento más racional desde el punto de vista económico y de eficacia. La obra estrella alrededor de la cual se desarrolla la creación, primero de una Comisión Gestora y finalmente del CAMB, es el «proyecto para el abastecimiento y saneamiento a los municipios de la Marina Baja», con un coste inicial estimado en 227 millones de pesetas -unos 1.364.298 euros-financiado en un 35\% por el Estado, y el restante $65 \%$ entre los ayuntamientos beneficiarios.

En la actualidad, forman parte del CAMB la Diputación Provincial de Alicante, la Confederación Hidrográfica del Júcar y los Ayuntamientos de Alfàs del Pi, Altea, Benidorm, Finestrat, Polop, La Nucía y La Vila Joiosa, todos ellos de la Provincia de Alicante. El peso de los ayuntamientos participantes reflejado en sus estatutos, dejó claramente establecida la relación de poder e influencia en la toma de decisiones del incipiente consorcio. Estos porcentajes se fijaron en: un 59,09\% para Benidorm, un 14,68\% para Villajoyosa, un 13,60\% para Altea, un 4,29\% para Alfaz del Pí, 3,65\% para la Nucía, 2,87\% para Callosa de Ensarriá, un 1\% para Polop, y finalmente, un 0,78\% para Finestrat. Los estatutos del CAMB datan de 1977 y siguen vigentes hasta la fecha tras varios intentos fallidos de modificación. Los motivos del establecimiento de los porcentajes a cada uno de los municipios no están recogidos explícitamente en la documentación consultada. Sin embargo, en mayo de 1970, esos porcentajes aparecían ligados a las dotaciones, en litros por segundo, que cada uno de los municipios recibiría para el abastecimiento de su población en el marco del «Proyecto de abastecimiento a los municipios de Marina Baja» mencionado (Actas CAMB, Reunión del 6 de mayo de 1970, Palacio de la Diputación de Alicante).

La Comisión Gestora del CAMB se constituyó en mayo de $1972^{13}$, no sin algunas modificaciones posteriores. El 22 de diciembre de ese mismo año y con motivo de la presentación del anteproyecto de Estatutos del futuro consorcio, el elevado peso de Benidorm -poseía casi el 60\% del capital- en comparación con el resto de municipios planteaba algunos problemas. La solución vendría a través del establecimiento de

12 Del 23 de mayo de 1972, de la Comisión Gestora del CAMB.

13 Para la formalización final del CAMB se requería autorización del Ministerio de la Gobernación a ayuntamientos y Diputación y autorización a la CHJ por parte del Ministerio de Obras públicas, y su DGOH.

112 La primera de esas autorizaciones se firmó el 16 de octubre de 1974 y la segunda el 28 de julio de 1977. 
dos tipos de voto de naturaleza diferente, el voto proporcional y el voto representativo según contemplaba la Ley de Régimen Local para las agrupaciones forzosas. De esta forma, si bien Benidorm seguiría teniendo una indudable influencia, no siempre el resto de ayuntamientos tendrían que estar sometidos a su voluntad.

El CAMB es titular de las concesiones de agua que se le otorguen para el abastecimiento común -los caudales reservados por la Confederación Hidrográfica del Júcar-. Sin embargo, los derechos previos de aprovechamiento de las aguas que hayan sido otorgadas a favor de los municipios que lo integran seguirán perteneciendo a ellos, sin perjuicio que se pueda acordar la incorporación de los mismos al CAMB (artículo 45, Estatutos del CAMB).

La complejidad de este organismo y su relación con los otros usuarios de la comarca radica fundamentalmente en la necesidad de la utilización conjunta de los caudales de la zona y las infraestructuras hídricas y la competencia por los recursos disponibles que, en épocas de sequía sobre todo, provocan la mayoría de los conflictos recogidos desde su creación. El mantenimiento de un equilibrio aceptable entre la demanda de recursos para actividades agrícolas muy productivas en determinadas zonas del interior de la comarca y la demanda creciente de un sector tan relevante como el turismo en la zona, no es una tarea sencilla, aunque la habilidad del CAMB para con el resto de usuarios, ha permitido alcanzar, a lo largo de los años una armonía plausible.

A lo largo de los casi cuarenta años de vida del CAMB han sido muchos los acontecimientos relevantes que han amenazado su permanencia. Desde problemas financieros muy graves por la falta de un compromiso firme de pago por parte de los miembros ${ }^{14}$, a polémicas entre los mismos por intereses contrapuestos -sin resolver a día de hoy-, como es el caso del municipio de Callosa d'En Sarriá15. Nuevas infraes-

14 Desde las primeras actas consultadas son muy frecuentes las reclamaciones a los diferentes municipios por las elevadas deudas contraídas con el CAMB, apareciendo incluso en la prensa -Diario INFORMACION 31/05/80, p. 25- la posibilidad de desaparición por la quiebra financiera del organismo, o las diversas demandas de Hidroeléctrica a la Consellería de Industria, Comercio y Turismo, en donde solicitaba el corte del suministro en 1984 ante una deuda impagada de más de 480.000 euros correspondientes a los meses de junio a octubre de ese año (Acta de 20 de diciembre de 1984, Junta General del CAMB). Ocho años después, la situación seguía siendo la misma, a la eléctrica, ahora Iberdrola, se le adeudaban en 1992, 1.894.460,00 euros, más 106.660,00 euros en concepto de intereses de demora, pasando estas deudas a tener carácter preferente para el CAMB a raíz de sus argumentaciones jurídicas. (Acta de 16 de marzo, de la Junta General del CAMB).

15 Este municipio planteó su separación del CAMB en la reunión de la Junta General en septiembre de 1988, aunque en 1987 ya amenazó con solicitarlo, alegando que los intereses del CAMB y de Callosa divergían demasiado. Varias informaciones aparecidas en prensa ya apuntaban hacia esta dirección. Un comunicado conjunto entre el ayuntamiento de Callosa, la Cámara Agraria Local y la Comunidad General de Regantes y Usuarios de Callosa, publicado en agosto de 1988, destacaba su predisposición a colaborar en resolver los problemas del agua en la zona, pero no apoyando «proyectos y obras que nacen con una vida útil de 5 años, que no resuelve el problema de fondo, sino que tan solo es un parche momentáneo» en clara referencia a las obras planteadas para la elevación de las aguas de los pozos de Callosa al pantano de Guadalest (Diario INFORMACION, 30/08/84 y 02/09/88). En junio de 1990 Callosa presenta un escrito a 
tructuras, acuerdos entre el CAMB y comunidades de regantes ${ }^{16}$ para utilizaciones conjuntas tanto de recursos como de infraestructuras, problemas de índole política, han estado continuamente presentes en la vida cotidiana del CAMB.

En la actualidad la polémica viene servida por la aprobación de un proyecto ${ }^{17}$ - «Proyecto para la mejora del abastecimiento urbano de los municipios de la Marina Baja»- al amparo de la Ley 11/2005 de modificación del Plan Hidrológico Nacional (en adelante PHN), dentro de las actuaciones del Anexo III y IV ${ }^{18}$. El mismo, tiene como objetivo aumentar la disponibilidad de los recursos hídricos en la comarca, para paliar la «sobreexplotación de acuíferos y el déficit de abastecimiento» que el propio Plan

la Junta General del CAMB solicitando su separación del mismo, argumentando que está sufragando obras que no benefician en modo alguno a su municipio. Esta solicitud es desestimada por aparecer el municipio como deudor de más de 345.000 euros al CAMB, no aceptando su solicitud hasta tanto no satisfaga estas cantidades (Acta de 2 de julio de 1990, Junta General CAMB). El Consistorio de Callosa, ante la reclamación de esas cantidades argumenta que no son reales, ya que si se le resta lo que el propio CAMB le adeuda por caudales asignados y no consumidos, en sintonía con las compensaciones anuales que se realizan entre municipios por caudales consumidos, esta deuda prácticamente queda compensada. Según nuestros cálculos, esto asciende a unos 290.450 euros, desde el año 1988 en que Callosa dejó de consumir, hasta 1992, año en que deja de aparecer en las actas como socio. Esta desaparición no viene justificada en los documentos en ningún momento, ya que lo único que aparece en el acta de 24/02/1992 son las palabras del presidente, Antonio Mira-Perceval, afirmando que «en virtud de acuerdos tomados en el Pleno Municipal, Callosa decidió separarse del CAMB, por lo que habrá que tomar las medidas oportunas para ello», sin mediar más explicación de lo que ocurrió posteriormente. Documentación facilitada por el propio Ayuntamiento de Callosa muestra cómo existe constancia de un acuerdo del Pleno del Ayuntamiento de 20 de marzo de 1990 en que se «procede a la salida del CAMB». Esta salida viene avalada por entidades como la Comunidad General de Usuarios de Callosa, con fecha 7 de abril de 1989.

16 Desde su creación, el CAMB ha tenido que lidiar con los que desde tiempos inmemoriales ostentan el derecho de uso del recurso. La colaboración con regantes ha sido siempre imprescindible, dando como resultado la firma de numerosos convenios de colaboración para la utilización conjunta de infraestructuras y recursos. Los convenios suscritos hasta el momento, aunque con sucesivas modificaciones y renovaciones, afectan al Sindicato Central de Usuarios de las cuencas de los ríos Algar y Guadalest, a la Comunidad de Regantes de Villajoyosa, Comunidad de Regantes Canal Bajo del Algar, Comunidad de Regantes de Altea, Comunidad de Regantes de Polop y Comunidad de Regantes de la Nucía. Recientemente ha sido acordada la firma de un controvertido convenio entre el CAMB y la Comunidad General de Regantes y Usuarios de Callosa d'En Sarriá, relevante por lo histórico de los problemas que intentan solucionar. Sería la primera vez que de manera oficial se plasma en un documento escrito algún acuerdo entre ambos organismos. El CAMB intentaba regular la colaboración que desde hace muchos años existe con esta Comunidad General por el mantenimiento de infraestructuras y gastos corrientes a que el CAMB hace frente a cambio de la utilización de los caudales del acuífero del Algar. La Comunidad General, que mantenía este convenio bloqueado desde septiembre de 2006, ha accedido por fin a regularizar estos ingresos por parte del CAMB, si bien se ha excluido la cláusula de utilización conjunta del acuífero que el Consorcio solicitaba y al que los regantes se oponían de lleno. Hay un pacto verbal, no suscrito mediante ningún documento, en virtud del cual la Comunidad General de Regantes y Usuarios de Callosa d'En Sarrià explota y controla el acuífero del Algar y cede los excedentes de agua al Consorcio de la Marina Baja para el abastecimiento de los distintos municipios que lo integran. A cambio de esta cesión, el ente comarcal del agua asume el pago de los gastos de explotación de los pozos, así como el mantenimiento y financiación de algunas obras en las distintas redes de regadío del municipio. (Diario Información, 21/07/2007).

17 El proyecto informativo está publicado en el BOE 38, de 1302/2007.

18 Anexo III, 3. Cuenca Hidrográfica del Júcar, q) Mejora del abastecimiento urbano de los municipios de la Marina Baja a través del canal bajo del Algar y el Anexo IV, 3. Cuenca del Júcar; 3.1 Actuaciones de aumento de la disponibilidad de recursos, j) Mejora del abastecimiento urbano de los municipios de la 114 Marina Baja a través del canal bajo de Algar., Ley 11/2005, de 22 de junio, de modificación del PHN. 
Hidrológico de la Cuenca del Júcar ${ }^{19}$ establece en unos $80 \mathrm{Hm}^{3}$. Este proyecto requiere la construcción de una instalación complementaria al Canal Bajo del Algar, que si bien es una infraestructura básica en el esquema de funcionamiento de la comarca de la Marina Baja, viene sufriendo continuas reparaciones y mejoras que en ocasiones suponen pérdidas de caudales importantes. La falta de acuerdo entre los municipios afectados, fundamentalmente Callosa d'En Sarriá, el CAMB y la empresa ACUAMED, encargada de la ejecución del mismo, mantienen de momento paralizado el proyecto en espera de la resolución de las alegaciones presentadas. Lo curioso de la obra es que un proyecto muy similar fue el que dio origen al CAMB en los años setenta, facilitando la integración física de los recursos en la zona.

En cierta medida, los ayuntamientos pertenecientes al CAMB han cedido parte de sus competencias en lo que a abastecimiento de aguas se refiere, aunque no todas ya que el consorcio se encarga fundamentalmente del abastecimiento en alta, llegando los caudales a los depósitos reguladores de cada uno de los municipios y correspondiendo entonces al consistorio su distribución final entre los ciudadanos, lo que se denomina abastecimiento en baja. La Ley $7 / 1985 \mathrm{LBRL}^{20}$, en su artículo 25 establece que «el municipio ejercerá, en todo caso, competencias en los términos de la legislación del Estado y de las Comunidades Autónomas, en: [... ] suministro de agua, [...] alcantarillado y tratamiento de aguas residuales.» De igual forma, esta Ley establece en su artículo $85.2^{21}$ que: «Los servicios públicos de la competencia local -entre los que encontramos el servicio de abastecimiento de aguas y saneamiento- podrán gestionarse mediante alguna de las siguientes formas: A) Gestión directa: a. Gestión por la propia entidad local; b. Organismo autónomo local; c. Entidad pública empresarial local; d. Sociedad mercantil local, cuyo capital social pertenezca íntegramente a la entidad local o a un ente público de la misma. B) Gestión indirecta, mediante las distintas formas previstas para el contrato de gestión de servicios públicos en el artículo 156 del texto refundido de la Ley de Contratos de las Administraciones Públicas, aprobado por el Real Decreto Legislativo 2/2000, de 16 de junio». Sin embargo, el hecho de que la titularidad del servicio recaiga sobre el ayuntamiento no implica que sea la propia corporación quien deba gestionarlo, sino que la legislación vigente ofrece diversas posibilidades para que cada municipio, por sí solo o de manera conjunta -el artículo 87 de la LRBRL establece la posibilidad de formar consorcios con otras Administraciones públicas para fines de interés común o con entidades privadas sin ánimo de lucro que persigan fines de interés público, concurrentes con los de las administraciones públicas- elija la forma de gestión que más le convenga.

19 Artículo 24.15 del Documento de Síntesis del PHCJ, CHJ (1999).

20 Modificada por Ley 24/2001, de 27 de diciembre, de Medidas Fiscales, Administrativas y del Orden Social; Ley Orgánica 14/2003, de 20 de noviembre, de Reforma de la Ley orgánica 4/2000, de 11 de enero, sobre derechos y libertades de los extranjeros en España y su integración social, Ley 57/2003, de 16 de diciembre, de medidas para la modernización del gobierno local. También se ha aprobado el RD Legislativo 2/2004, de 5 de marzo, por el que se aprueba el texto refundido de la Ley Reguladora de las Haciendas Locales.

21 Redactado según Ley 57/2003. 
Según la encuesta de AEAS (2004), la gestión pública bien sea por medio de un ente público, sociedad pública o consorcio, alcanza al 40\% de la población, representando una disminución de 5 puntos con respecto a la última encuesta de 2002, la gestión por empresa privada a un $36 \%$, por empresas mixtas un $16 \%$ de la población, lo que supone un incremento si lo comparamos con el 11\% que suponían en la encuesta de 2002, y la gestión directa de la propia corporación local, al 7\%, siendo los municipios de menos de 5.000 habitantes los que más utilizan esta forma de gestión directa.

Sin embargo, estos datos generales deben ser matizados en lugares como por ejemplo Barcelona, Bilbao, Madrid o la propia comarca de la Marina Baja. En el área de Barcelona, Aigües del Ter Llobregat gestiona el suministro de agua en alta, en tanto que Aguas de Barcelona se encarga del servicio de distribución en baja y lo mismo ocurre en el área de influencia del CAMB, que presta el servicio de abastecimiento en alta, mientras que el servicio de abastecimiento en baja de los municipios que lo integran se presta a través de empresas privadas como Aquagest y Aqualia. El Consorcio de Aguas Bilbao Bizkaia se encarga del abastecimiento en alta a los 54 municipios que lo integran, prestando además el servicio en baja del área metropolitana de Bilbao y de 19 municipios más, siendo de gestión directa por los propios ayuntamientos los 35 restantes (Fernández, 2002). El Canal de Isabel II gestiona el ciclo integral del agua en la Comunidad de Madrid, sin embargo el saneamiento de la ciudad lo gestiona directamente el ayuntamiento.

En el caso de la provincia de Alicante la gestión es predominantemente indirecta, abarcando al $88,6 \%$ de la población de la provincia. De las modalidades de gestión indirecta, un $51,6 \%$ se desarrolla a través de empresas mixtas y un $48,4 \%$ por concesión a empresas privadas. A nivel comarcal, de los dieciocho municipios que componen la Marina Baja, en diez de ellos el servicio de abastecimiento en baja es prestado directamente por el ayuntamiento, aunque esto supone solamente el 8,66\% del total de la población de la comarca; en otros ocho es la empresa Aquagest Levante S.A.22 a través de concesión -o Aqualia para el caso del municipio de la Nucía- quien presta el servicio, todos ellos a excepción de la localidad de Orcheta, pertenecientes al CAMB. Estos municipios representan el 91,34\% de la población de la comarca, lo que claramente muestra la preferencia por la gestión indirecta, al menos en cuanto a lo que el servicio de abastecimiento en baja se refiere.

22 Es una de las empresas de gestión integral del ciclo hídrico más implantada en el sureste español. Opera en la Comunidad Valenciana desde 1969, y pertenece al Sector de Agua y Saneamiento del Grupo Agbar. Así mismo, Aquagest Levante forma parte de empresas mixtas tan relevantes en la zona como Agamed para la ciudad de Torrevieja, Aguas Municipalizadas de Alicante, Aigües D’Elx o Emarasa. El Grupo Agbar es un gran holding constituido por más de 250 empresas y con más de 130 años de historia que opera en todos los ámbitos relacionados con los servicios a la colectividad: ciclo integral del agua, salud, certificación e inspección, instalaciones y transporte, entre otros. Agbar Agua está constituida por el conjunto de sociedades pertenecientes al Grupo Agbar que se dedican a la gestión del ciclo integral del agua, es decir, a 116 la captación, transporte, potabilización y distribución de agua potable, así co 
La preferencia por una u otra forma de gestión depende de numerosos factores, aunque los datos demuestran, y así lo corrobora el Libro Blanco del Agua (MIMAM, 2000, p.278) que «En pequeños núcleos de población, donde la gestión es realizada de forma independiente por cada ayuntamiento, no siempre se dispone de un tratamiento adecuado. Las ciudades de mayor entidad, por el contrario, no presentan este problema, siendo aceptable, en general, la calidad del agua suministrada. A este respecto, en algunos casos se aprecian importantes diferencias en la calidad de los servicios obtenidos en núcleos grandes y pequeños. En los primeros, al poder contar con Organismos o empresas especializadas, suelen alcanzarse niveles de servicio más eficientes y de mayor calidad, mientras que en los segundos, sobre todo en el caso de pequeños Ayuntamientos, pueden llegar a presentarse problemas incluso para obtener un adecuado tratamiento de las aguas potables. Ello ha dado lugar a que cada vez sea más frecuente la integración de pequeños y medianos municipios en órganos supramunicipales que prestan servicios a los ayuntamientos integrados en dicho órgano. Con ello, como se ha mencionado, además de una mayor tecnificación de la gestión y seguridad de suministro, es posible obtener una disminución de los costes. Existen muchos pequeños núcleos, sin embargo, que se abastecen de pozos y manantiales en buenas condiciones, lo que supone una senciIla y económica solución a nivel municipal». Otros autores como Hall (2005) argumentan que la gestión pública de los servicios de agua viene siendo una solución viable en muchos países en donde el fracaso de las privatizaciones ocurridas en la década de los 90 se ha hecho evidente.

\section{FUNCIONAMIENTO ECONÓMICO-PRESUPUESTARIO DEL CAMB}

EI CAMB, que integra a los municipios de Alfaz del Pí, Altea, Benidorm, Finestrat, Polop, La Nucía y Villajoyosa, a la Diputación Provincial de Alicante, y a la CHJ como hemos mencionado, nació como una entidad encargada de la captación de recursos y la distribución en alta de agua potable en la comarca de la Marina Baja. La importancia de cada uno de los municipios en el funcionamiento del consorcio no es homogénea. Depende de numerosos factores, -población, extensión, relevancia en la comarca, etc.- y por tanto, su representación tampoco es uniforme. La mayor o menor relevancia de cada uno viene determinada fundamentalmente según su aportación económica.

Los Estatutos, en su artículo 22, determinan dos tipos de votos para los municipios consorciados: un voto denominado de representación que es igual para todos, y el llamado voto proporcional que pondera el grado de aportación de cada municipio a las inversiones del CAMB. De esta forma se intentaba impedir, al menos en teoría, que municipios con una relevancia indiscutible, tuviesen la llave de todas y cada una de las decisiones del CAMB. La tabla adjunta nos ofrece una muestra de esta disparidad en cuanto a la participación, y el motivo de porqué era necesario introducir algún mecanismo corrector de la participación. 
TABLA 1

Participación de los municipios consorciados en el CAMB

\begin{tabular}{|l|c|}
\hline & \% según Estatutos \\
\hline Altea & 14,00 \\
\hline Alfaz del Pi & 4,43 \\
\hline Benidorm & 60,87 \\
\hline Finestrat & 0,82 \\
\hline La Nucía & 3,71 \\
\hline Polop & 1,03 \\
\hline Villajoyosa & 15,14 \\
\hline TOTAL & 100,00 \\
\hline
\end{tabular}

Fuente: Estatutos del CAMB.

Estos porcentajes determinan, como se ha mencionado, tanto cantidades económicas como actuaciones de cada uno de los municipios dentro del CAMB. La determinación y el cálculo de las aportaciones presupuestarias anuales y su distribución entre los consorciados, sigue un procedimiento sencillo. Con el presupuesto inicial establecido se deduce qué parte corresponde a gastos fijos y cuál a gastos variables. Así, por ejemplo el presupuesto del año 2005. La distribución de los gastos es la siguiente:

TABLA 2

Distribución de gastos fijos y variables para el presupuesto del CAMB de 2005

\begin{tabular}{|c|c|}
\hline Concepto & Euros \\
\hline Personal & $975.727,90$ \\
\hline Cánones & $1.954 .296,35$ \\
\hline Convenio Regantes & $470.804,82$ \\
\hline Iberdrola & $361.443,71$ \\
\hline TOTAL GASTOS FIJOS & $3.762 .272,78$ \\
\hline TOTAL GASTOS VARIABLES & $4.900 .736,52$ \\
\hline PRESUPUESTO AÑO 2005 & $8.663 .009,30$ \\
\hline
\end{tabular}

Fuente: Elaboración propia a partir de las actas del CAMB.

La aportación de cada municipio consorciado a los gastos fijos se establece en 118 función del porcentaje de participación que fijan los estatutos: 
TABLA 3

Porcentaje según estatutos y cantidad a aportar para el año 2005

\begin{tabular}{|l|c|c|}
\hline & \% según Estatutos & Cantidad a aportar \\
\hline Altea & 14,00 & $526.718,19$ \\
\hline Alfaz & 4,43 & $166.668,68$ \\
\hline Benidorm & 60,87 & $2.290 .095,44$ \\
\hline Finestrat & 0,82 & $30.850,64$ \\
\hline La Nucía & 3,71 & $139.580,32$ \\
\hline Polop & 1,03 & $38.751,41$ \\
\hline Villajoyosa & 15,14 & $569.608,10$ \\
\hline TOTAL & 100,00 & $3.762 .272,78$ \\
\hline
\end{tabular}

Fuente: Elaboración propia a partir de las actas del CAMB.

Una vez calculada la parte de los gastos fijos que debe afrontar cada municipio, se procede al cálculo de la participación en los gastos variables. Esta participación varía cada año, atendiendo al consumo realizado el año anterior disponible. Es decir, para calcular la parte variable del presupuesto del año 2005, que normalmente se aprueba a finales de 2004, se utilizan las cantidades efectivamente consumidas en 2003, año en que se tienen contabilizados los datos relativos al consumo anual. Con estas cifras, se determina el peso que cada municipio ha tenido en relación al consumo total del año 2003 y se expresa en porcentajes. Esos porcentajes son los que se utilizan para distribuir los gastos variables de cara al cálculo del presupuesto de 2005.

TABLA 4

Participación de cada municipio en el consumo total de 2003

\begin{tabular}{|l|c|c|}
\hline & \% según consumo 2003* & Cantidad a aportar \\
\hline Altea & 5,75 & $282.001,62$ \\
\hline Alfaz & 11,49 & $563.139,50$ \\
\hline Benidorm & 59,79 & $2.930 .097,47$ \\
\hline Finestrat & 2,64 & $129.400,24$ \\
\hline La Nucía & 8,72 & $427.345,57$ \\
\hline Polop & 0,00 & 0,00 \\
\hline Villajoyosa & 11,61 & $568.752,11$ \\
\hline TOTAL & 100,00 & $4.900 .736,52$ \\
\hline
\end{tabular}

* El total consumido en 2003 fue de 21.464.395 m³, correspondiendo a Alfaz, 2.466.429 m³; Altea, 1.235.106 m³; Benidorm, 12.833.43 m³; Finestrat, 566.745 m³; La Nucía, 1.871.681 m³; Polop no consumió nada del CAMB y Villajoyosa, 2.491.011 $\mathrm{m}^{3}$. Los porcentajes se han calculado en base a estos consumos.

Fuente: Actas del CAMB de la Sesión Extraordinaria de 8 de noviembre de 2004. 
La aportación total al presupuesto de 2005 es la suma de ambas cantidades:

\section{TABLA 5}

Distribución del presupuesto de 2005 entre los municipios consorciados

\begin{tabular}{|l|r|r|r|r|r|}
\hline & $\begin{array}{c}\text { \% según } \\
\text { Estatutos }\end{array}$ & $\begin{array}{c}\text { Cantidad a } \\
\text { aportar }\end{array}$ & $\begin{array}{c}\text { \% según } \\
\text { consumo } \\
\mathbf{2 0 0 3}\end{array}$ & $\begin{array}{c}\text { Cantidad a } \\
\text { aportar }\end{array}$ & Total 2005 \\
\hline Altea & 14,00 & $526.718,19$ & 5,75 & $282.001,62$ & $808.719,81$ \\
\hline Alfaz & 4,43 & $166.668,68$ & 11,49 & $563.139,50$ & $729.808,18$ \\
\hline Benidorm & 60,87 & $2.290 .095,44$ & 59,79 & $2.930 .097,47$ & $5.220 .192,91$ \\
\hline Finestrat & 0,82 & $30.850,64$ & 2,64 & $129.400,24$ & $160.250,88$ \\
\hline La Nucía & 1,03 & $139.580,32$ & 8,72 & $427.345,57$ & $566.925,89$ \\
\hline Polop & 15,14 & $569.608,10$ & 11,61 & $568.752,11$ & $1.138 .360,21$ \\
\hline Villajoyosa & 100,00 & $3.762 .272,78$ & 100,00 & $4.900 .736,52$ & $8.663 .009,30$ \\
\hline TOTAL & & $38.751,41$ & 0,00 & 0,00 & $38.751,41$ \\
\hline
\end{tabular}

Fuente: Elaboración propia a partir de las actas del CAMB.

Con el objetivo de incentivar de algún modo un consumo estable a lo largo de los años entre los municipios, el CAMB realiza tradicionalmente una práctica reseñable en cuanto al cómputo de consumos. Son las llamadas compensaciones, que se calculan anualmente, tratando de recompensar a aquellos municipios que con respecto al año anterior se han mantenido en sus previsiones de consumo o incluso lo han reducido, y sancionando de alguna forma a aquellos que han tenido un consumo excesivo o superior al inicialmente previsto.

La forma de determinar estas actuaciones también viene referenciada al consumo de años anteriores. Para calcular las compensaciones del año 2004 por ejemplo, se utilizan los consumos de 2003, y el peso relativo que el consumo total ha tenido para cada municipio.

\section{TABLA 6}

Cálculo de las compensaciones entre municipios en 2004 en base al consumo del año anterior

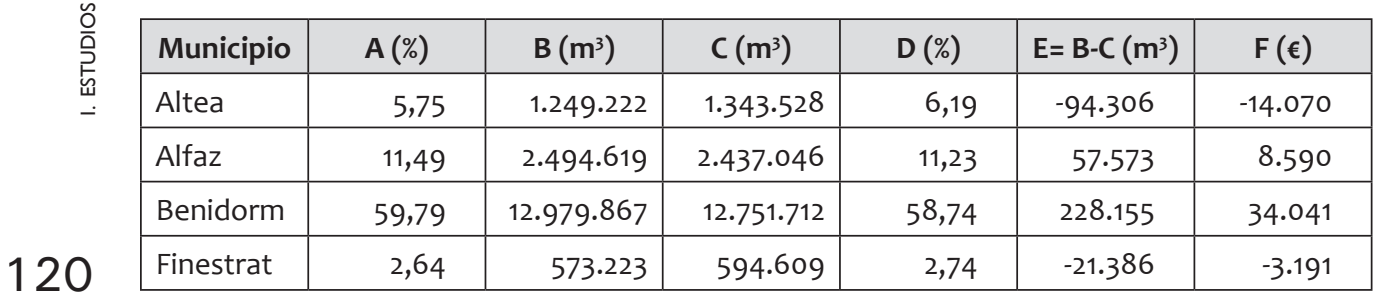


TABLA 6 (cont.)

Cálculo de las compensaciones entre municipios en 2004 en base al consumo del año anterior

\begin{tabular}{|l|r|r|r|r|r|r|}
\hline Municipio & A $(\%)$ & \multicolumn{1}{c|}{$\mathbf{B}\left(\mathbf{m}^{3}\right)$} & $\mathbf{C}\left(\mathbf{m}^{3}\right)$ & D $(\%)$ & E= B-C $\left(\mathbf{m}^{3}\right)$ & F $(\boldsymbol{\epsilon})$ \\
\hline La Nucía & 8,72 & 1.893 .073 & 2.034 .514 & 9,37 & -141.441 & -21.103 \\
\hline Polop & 0,00 & 0 & 0 & 0,00 & 0 & 0 \\
\hline Villajoyosa & 11,61 & 2.519 .482 & 2.548 .076 & 11,74 & -28.594 & -4.266 \\
\hline TOTAL & 100,00 & 21.709 .485 & 21.709 .485 & 100,00 & 0 & 0 \\
\hline
\end{tabular}

A: porcentaje según consumo total efectuado en 2003. Representa el peso de cada municipio sobre el total consumido por el CAMB en 2003.

B: consumo estimado por municipio del total consumido en 2004, utilizando los porcentajes de la columna A. Es decir, teniendo la cifra total de consumo en 2004, si los municipios hubiesen seguido el comportamiento del año anterior, cuanto hubiesen consumido.

C: consumo efectivo realizado por cada municipio en 2004.

D: porcentaje de participación del consumo individual en el consumo total de 2004, en base a la columna C.

E: diferencia entre lo estimado en base a 2003 y lo consumido en 2004 (A-C).

F: Saldo a favor o en contra del CAMB según los 0,1492 €/m³ calculados para realizar las compensaciones en 2004 .

Fuente: Elaboración propia.

La tabla anterior muestra que aquellos municipios que han consumido más de lo que teóricamente deberían, en función del comportamiento del año anterior, deberán pagar ese exceso de consumo a aquellos municipios cuyo consumo ha sido inferior al estimado. La suma de las compensaciones es cero y se restan o se suman, según el caso, a las aportaciones que cada municipio debe realizar anualmente al CAMB.

Estas compensaciones son más simbólicas que significativas, ya que representan un porcentaje muy pequeño del presupuesto total municipal, siendo su principal objetivo el de incentivar al ahorro y concienciar a los consorciados de la necesidad de controlar el consumo de agua. El precio por metro cúbico consumido en exceso -o dejado de consumir - varía cada año en función del consumo global del CAMB y se calcula según la liquidación de presupuestos del año a compensar. Para el 2004, el presupuesto liquidado ascendió a 5.451.121,31; la parte variable fue de 3.238.703,12 ${ }^{23}$, y el volumen total consumido en ese año, de 21.709.485 $\mathrm{m}^{3}$. Esto nos da una cifra de 0,1492 euros por metro cúbico a compensar.

Si analizamos el comportamiento de los municipios a través de las compensaciones desde los años ochenta, observamos que algunos municipios consumen tradicionalmente por encima de lo estimado -Alfaz, Benidorm, La Nucía-, y otros, suelen tener exceso de $\mathrm{m}^{3}$, como puede ser el caso de Altea, Villajoyosa o Polop.

23 Acta de la sesión extraordinaria de 26 de julio de 2005. 


\section{TABLA 7}

Metros cúbicos consumidos en exceso o sobrantes en base a lo estimado y $€ / \mathrm{m}^{3}$ para su compensación

\begin{tabular}{|c|c|c|c|c|c|c|c|c|c|}
\hline Año & Alfaz & Altea & Benidorm & Callosa & Finestrat & La Nucía & Polop & Villajoyosa & $\begin{array}{c}€ / \mathrm{m}^{3} \text { para } \\
\text { compensación }\end{array}$ \\
\hline 1983 & -272.610 & 844.194 & -805.638 & 0 & 112.489 & -292.264 & 0 & 413.829 & 0,0756 \\
\hline 1984 & -124.383 & 485.701 & -581.668 & 0 & 84.012 & -402.263 & 0 & 538.601 & 0,0912 \\
\hline 1985 & -399.842 & 1.178 .645 & -1.014 .494 & 0 & 41.312 & -269.576 & 0 & 463.955 & 0,1061 \\
\hline 1986 & -415.961 & 1.552 .945 & -1.502 .067 & 0 & -1.925 & -390.119 & 0 & 757.127 & 0,0902 \\
\hline 1987 & -435.182 & 1.849 .741 & -1.671 .159 & 0 & 34.686 & -357.360 & 0 & 579.274 & 0,0460 \\
\hline 1988 & -736.008 & 1.469 .010 & -1.509 .134 & 575.422 & -131.822 & -414.313 & 198.422 & 548.423 & 0,0981 \\
\hline 1989 & -760.664 & 1.773 .368 & -1.343 .533 & 568.768 & -94.828 & -693.893 & 196.127 & 354.654 & 0,0975 \\
\hline 1990 & -613.551 & 1.694 .483 & -1.322 .680 & 544.217 & -222.751 & -788.577 & 187.661 & 521.198 & 0,0932 \\
\hline 1991 & -794.317 & 1.566 .307 & -1.200 .592 & 547.556 & -339.610 & -592.607 & 188.812 & 624.451 & 0,1052 \\
\hline 1992 & -1.128 .922 & 1.466 .784 & -129.770 & 529.047 & -406.436 & -591.532 & 182.430 & 78.399 & 0,1326 \\
\hline 1993 & -1.022 .966 & 1.489 .999 & 41.788 & 0 & -252.455 & -662.594 & 204.912 & 201.316 & 0,1238 \\
\hline 1994 & -1.287 .122 & 1.562 .561 & 134.252 & 0 & -246.580 & -745.112 & 212.397 & 369.604 & 0,1239 \\
\hline 1995 & -1.317 .418 & 1.408 .968 & -246.314 & 0 & -309.782 & -612.208 & 200.664 & 876.090 & 0,1080 \\
\hline 1996 & -263.595 & -45.488 & 19.620 & 0 & -61.720 & -9.480 & 0 & 360.663 & 0,2686 \\
\hline 1997 & 337.848 & 91.794 & -519.631 & 0 & -130.359 & 13.510 & 0 & 206.838 & 0,2141 \\
\hline 1998 & 359.251 & 86.187 & -356.885 & 0 & -3.429 & -234.143 & 0 & 149.019 & 0,1439 \\
\hline 1999 & -109.921 & -40.577 & 763.508 & 0 & 133.354 & -336.511 & 0 & -409.853 & 0,2397 \\
\hline 2000 & nd & nd & nd & nd & nd & nd & nd & nd & 0,3270 \\
\hline 2001 & 51.235 & 1.572 & 472.219 & 0 & -44.466 & -91.924 & 0 & -388.636 & 0,3471 \\
\hline 2002 & -67.983 & 19.919 & -20.461 & 0 & 26.083 & 92.487 & 0 & -50.045 & 0,1442 \\
\hline 2003 & -3.438 & 53.865 & -3.642 & 0 & 12.186 & 39.038 & 0 & -98.009 & 0,1361 \\
\hline 2004 & 57.572 & -94.306 & 228.155 & 0 & -21.386 & -141.441 & 0 & -28.594 & 0,1492 \\
\hline
\end{tabular}

Fuente: Elaboración propia a partir de las actas del CAMB.

Recordemos que el porcentaje de participación de cada municipio determina, entre otros aspectos, las aportaciones económicas al CAMB. Si como se observa, es-

122 tas variaciones entre el consumo estimado según esos porcentajes y el consumo real

Revista de Estudios de la Administración Local y Autonómica 
son más o menos constantes en el tiempo -salvo años excepcionales en que cambia el signo-, lo más coherente sería modificar en los estatutos los porcentajes de participación y que el peso de cada municipio sea acorde a su realidad actual. Altea, por ejemplo, realiza aportaciones presupuestarias en función del porcentaje del $14 \%$ que se recoge en los estatutos, cuando su consumo anual ha estado históricamente entre el 5 y el $6 \%$ del total consumido en el CAMB. Con Alfaz del Pí ocurre lo contrario; mientras los estatutos le conceden una importancia dentro del CAMB del 4,43\%, su consumo anual ronda el $12 \%$ del total. ¿Por qué no se modifican entonces los estatutos? Altea ahorraría costes ya que una reducción de su peso significaría tener que contribuir con cantidades inferiores al mantenimiento del CAMB, y por otra parte, Alfaz, aunque tuviese que aumentar su aportación anual, tendría más peso en el organismo.

Ahí es donde radica el problema: el porcentaje de participación lleva aparejado una cuota de poder dentro del CAMB a la que no están dispuestos a renunciar aquellos municipios que tendrían que revisarlos a la baja, aunque ello suponga aportaciones inferiores. Por otro lado, aquellos municipios cuya participación en los gastos fijos es menor se ven beneficiados de una rebaja en sus aportaciones, aunque parte de ella se vea minorada a través de las compensaciones. Este es el motivo por el cuál, pese a los varios intentos -en enero de 1995 se llegó a aprobar un borrador de Estatutos, que nunca se convirtió en definitivo-, siguen estando vigentes los Estatutos aprobados en noviembre de 1977 (BOP 10/11/1977). Altea es el único municipio que llegó a plantear una reducción de su participación en 1989, del 13,6 al 3\%24. El presidente del CAMB en ese momento, Fernández Valenzuela, le indicó que seguro que se había precipitado al no haber considerado «las expectativas de expansión de su municipio, en un futuro no muy lejano». El Alcalde de Altea planteó entonces que «había municipios que teniendo una cuota menor, podían consumir en exceso pagando luego la cantidad consumida vía compensaciones, lo que resultaba más barato que el pago del agua por cuota». Sin embargo, el secretario explicó que no debían confundirse conceptos: una cosa son las compensaciones que se llevan a cabo entre los ayuntamientos, y otra muy distinta las aportaciones por cuota que tienen una parte fija en función de los gastos tanto corrientes como los de inversión. Todo quedó en un cambio de pareceres y en la intención de establecer una cifra más equitativa para todos.

Las cantidades presupuestadas por este organismo han ido en constante aumento, como era de esperar. Las tablas 8 y 9 nos muestran los presupuestos del CAMB desde 1978 hasta 2005, aunque gráficamente se observa mucho mejor la progresión.

Una de las partidas más relevantes es la referida al capítulo 4. Transferencias corrientes, del presupuesto de gastos. Es allí donde vienen recogidas las cantidades que anualmente el CAMB aporta a las comunidades de regantes con las que mantiene contacto, tanto a través de convenios, como a través de acuerdos verbales.

24 Acta de la Sesión ordinaria de la Junta General de 6 de noviembre de 1989. 


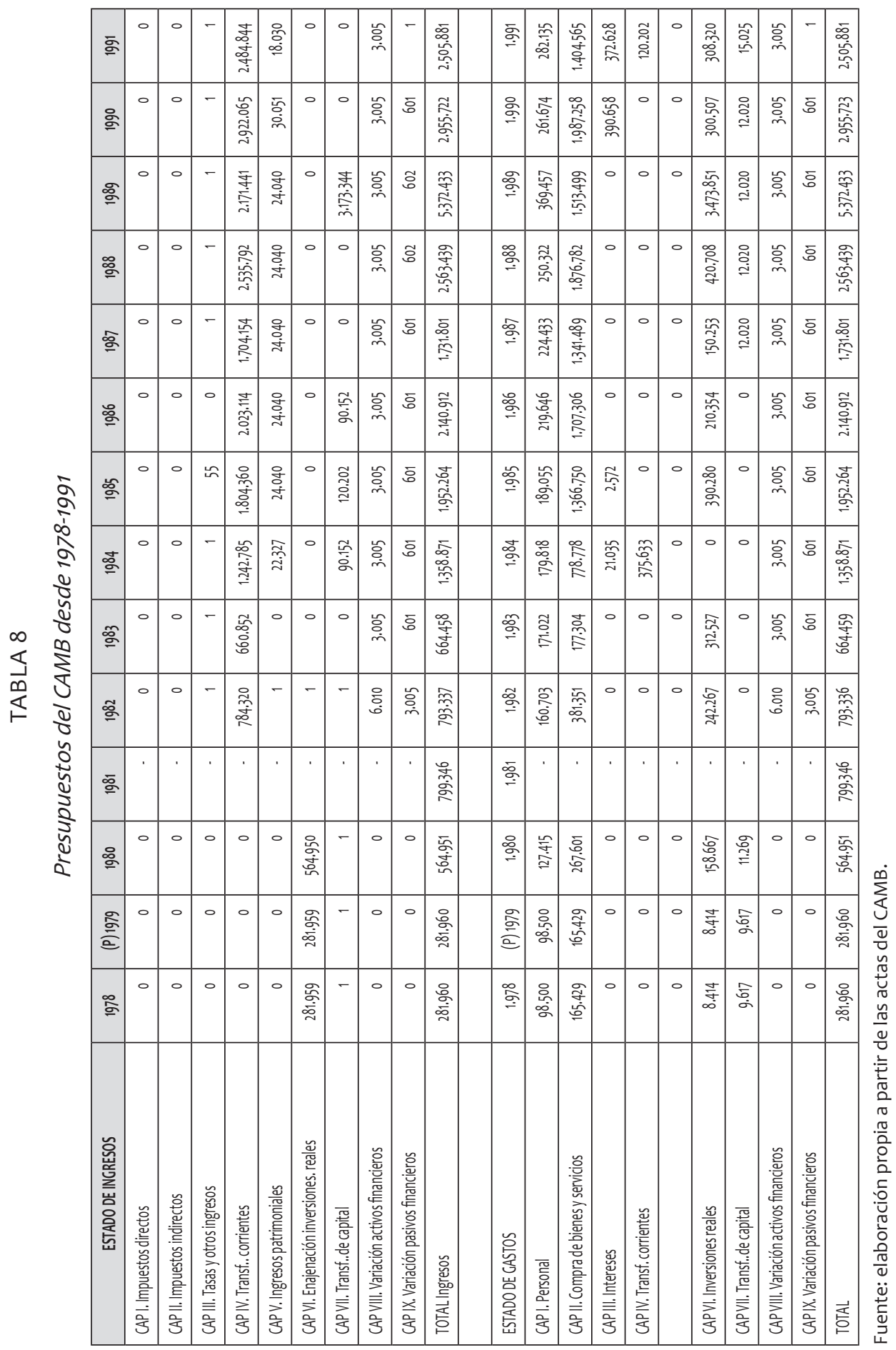

Revista de Estudios de la Administración Local y Autonómica 
EL FUNCIONAMIENTO ECONÓMICO DE UNA INSTITUCIÓN SUPRAMUNICIPAL CLAVE EN LA GESTIÓN DEL AGUA...

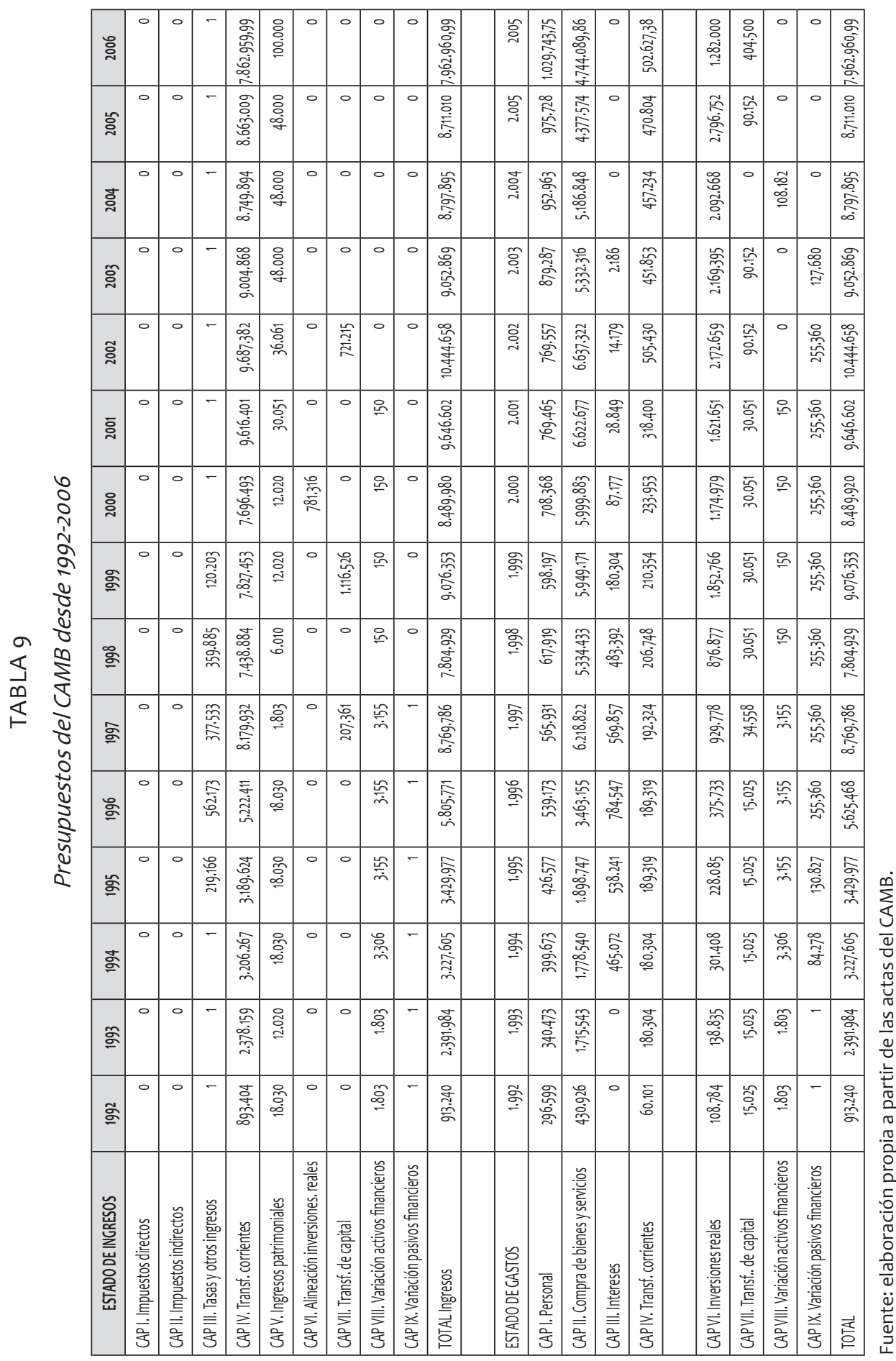




\section{GRÁFICO 1}

Evolución de los presupuestos del CAMB, 1978-2006

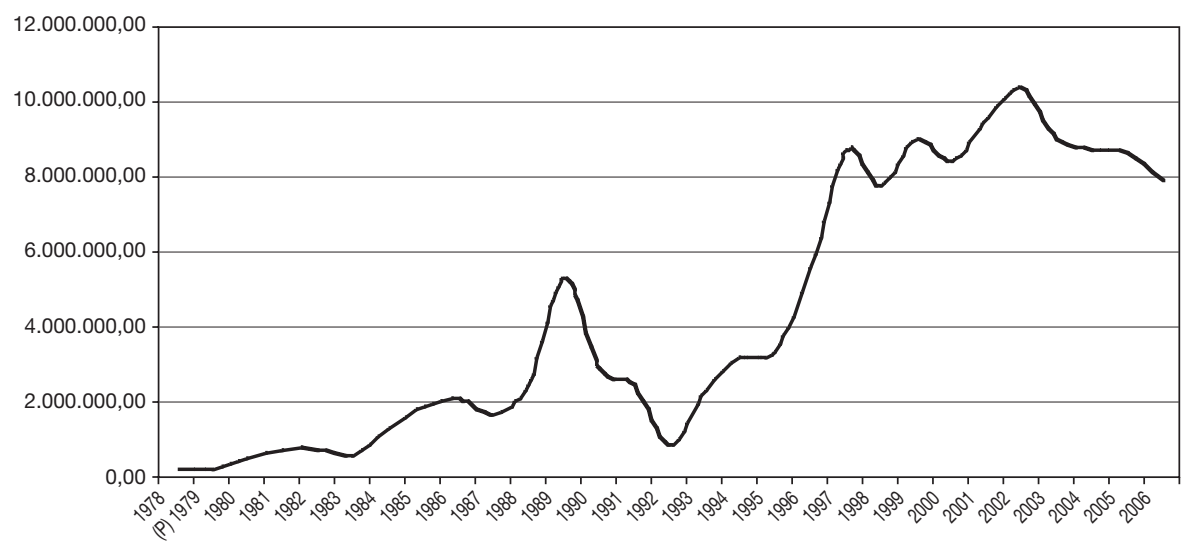

* Los presupuestos de 1990 recogen tanto la necesidad de financiar las obras de acondicionamiento del Canal Bajo del Algar 1. y 2. ${ }^{a}$ fase por unos presupuestos de ejecución de 441.154.381 ptas (2.651.391,3€), y otras obras de infraestructuras. Además, hubo que solicitar un préstamo con la Caja Provincial de Alicante por importe de 377.400 .000 ptas $(2.268 .220,00 €)$, lo que disparó las previsiones presupuestarias para ese año.

Si consideramos solamente esta cantidad desde que el CAMB se configuró en 1977, vemos que salvo alguna excepción, esta partida comienza a ser relevante a partir de 1991, coincidiendo con el primer convenio firmado con la comunidad de regantes de Villajoyosa ${ }^{25}$, en donde se establece el pago de una cantidad anual a los regantes de 54.000 euros, cantidad que será elevada hasta los 81.500 euros que reciben en la actualidad. Además de estos gastos, el CAMB debe afrontar una serie de facturas, generalmente derivadas de la energía eléctrica necesaria para las elevaciones y bombeos de caudales, que le presentan tanto los regantes de Callosa d'En Sarriá como Polop y Beniardá, por la utilización de los pozos en dichos términos municipales. Cantidades que por no existir convenio no tienen un carácter constante, pero nada despreciables si consideramos que el último enfrentamiento entre Callosa y el CAMB es por 422.000 euros correspondientes, según los regantes, a los gastos del agua de los años 2005 y $2006^{26}$.

25 El convenio se aprueba el 11 de junio de 1990 y se formaliza el 2 de junio de 1992.

26 Puede seguirse el conflicto hasta la firma de un convenio que recoge exclusivamente estos gastos y solo para dos años, en los que el CAMB se compromete a pagar a la comunidad de regantes de Callosa dicha cantidad. Diario Información, 21/07/2007 y actas del CAMB. 


\section{GRÁFICO 2}

Deudas totales de los municipios consorciados con el CAMB, 1978-2006

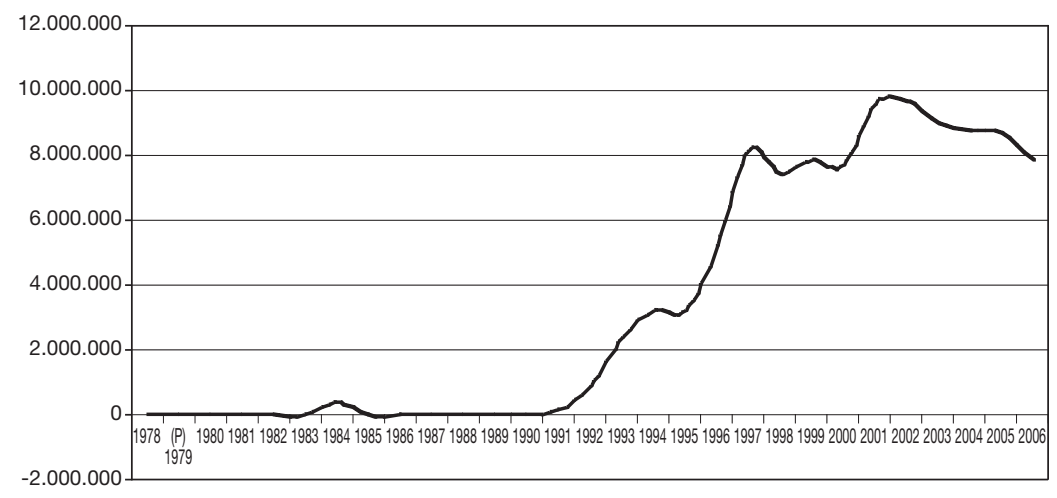

Fuente: Elaboración propia.

Este capítulo 4 forma parte de los gastos considerados como fijos, a los que los municipios consorciados deben hacer frente en función de los porcentajes de participación en el CAMB.

Una tónica general en la vida presupuestaria y económica del CAMB han sido las deudas. La falta de pago por parte de los municipios ha propiciado momentos de tensión en el seno del organismo: paralización de obras por falta de liquidez, dimisiones y amenazas de disolución, intentos de soluciones cuanto menos curiosas, aunque pese a todo, el CAMB sigue funcionando27.

La deuda más llamativa es la que ha venido manteniendo el CAMB con Hidroeléctrica primero e Iberdrola después. La compañía ha intentado iniciar por impago numerosas acciones legales, aunque por tratarse de un organismo cuyo objeto es ga-

27 Paralización de los sondeos en la zona de Beniardá (Acta de la Sesión Extraordinaria de la Junta General de 15 de mayo de 1982). En 1978, el Secretario del CAMB presentó su dimisión ante las informaciones aparecidas en prensa sobre la creación de un ente comarcal alternativo al consorcio, que contaba apenas 8 meses de vida legal. Alegaba la falta de interés por parte de los ayuntamientos de contribuir al buen funcionamiento del organismo y las eternas deudas que nunca se satisfacían (Acta de la Sesión de la Junta General de 6 de septiembre de 1978). En uno de los momentos se plantea, incluso, el corte de suministro a aquellos ayuntamientos que tengan deudas por encima de una cierta cantidad. Sin embargo, todo queda en una declaración de intenciones sin que llegue a materializarse (Acta de la Sesión Extraordinaria de la Junta General de 1 de julio de 1985). Otra de las propuestas hacía referencia a los ingresos que determinados ayuntamientos debían percibir por las ya mencionadas compensaciones; si estas eran a favor, se descontarían de sus cantidades adeudadas. El problema venía de que los mayores deudores eran también los poseedores de un saldo negativo para con el CAMB, por tanto la medida no resultaría muy efectiva. (Acta de la Sesión Extraordinaria de la Junta General de 4 de diciembre de 1985). El requerir el pago a través de la Delegación de Hacienda de la provincia de Alicante, también fue una de las propuestas (Acta de la Sesión Ordinaria de la Junta General de 3 de noviembre de 1986). 
rantizar el suministro de un bien considerado esencial como el agua, no han surtido efecto. Las deudas han llegado a las 258.503 .932 pesetas, más de un millón y medio de euros, por la falta de liquidez del CAMB, según detalla el acta de 20 de octubre de 1989.

En síntesis, en la siguiente tabla podemos observar esta falta de pago por parte de los municipios consorciados.

TABLA 10

Cantidades adeudadas por cada ayuntamiento en varios años

\begin{tabular}{|l|r|r|r|r|r|r|r|}
\hline Ayuntamiento & \multicolumn{1}{c|}{1972} & \multicolumn{1}{c|}{1980} & \multicolumn{1}{c|}{1985} & \multicolumn{1}{c|}{1990} & \multicolumn{1}{c|}{1995} & \multicolumn{1}{c|}{2000} & \multicolumn{1}{c|}{2006} \\
\hline Alfáz del Pi & 722,06 & $2.327,92$ & $15.426,13$ & $108.850,50$ & $332.590,60$ & $502.517,51$ & $429.124,87$ \\
\hline Altea & $10.597,74$ & $7.362,71$ & $287.553,56$ & $448.889,24$ & $859.732,97$ & $1.564 .486,49$ & $4.169 .829,37$ \\
\hline Benidorm & $40.985,73$ & $31.995,32$ & $1.146 .329,14$ & $1.681 .983,06$ & $6.734 .160,12$ & $4.118 .305,96$ & $2.757 .573,07$ \\
\hline Callosa & $2.297,62$ & $1.569,99$ & $103.536,17$ & $343.748,04$ & 0,00 & 0,00 & 0,00 \\
\hline Finestrat & 809,49 & 433,10 & $32.735,04$ & $20.251,25$ & $84.815,99$ & $63.549,97$ & $165.607,83$ \\
\hline La Nucía & $1.397,56$ & 541,37 & $60.242,21$ & $69.101,03$ & $160.208,51$ & $981.775,86$ & $580.675,67$ \\
\hline Polop & 655,70 & $1.948,96$ & $26.475,29$ & $48.812,36$ & $57.309,02$ & $91.626,50$ & $264.287,54$ \\
\hline Villajoyosa & $19.997,55$ & $7.958,23$ & $342.406,22$ & $607.779,97$ & $930.022,54$ & $1.255 .194,55$ & $2.552 .680,98$ \\
\hline TOTALES & $77.463,44$ & $54.137,60$ & $2.014 \cdot 703,78$ & $3.329 .415,46$ & $9.158 .839,75$ & $8.577 .456,85$ & $10.919 .779,33$ \\
\hline
\end{tabular}

Fuente: Elaboración propia a partir de las actas del CAMB.

\section{GRÁFICO 3}

Cantidades adeudadas por cada ayuntamiento en varios años

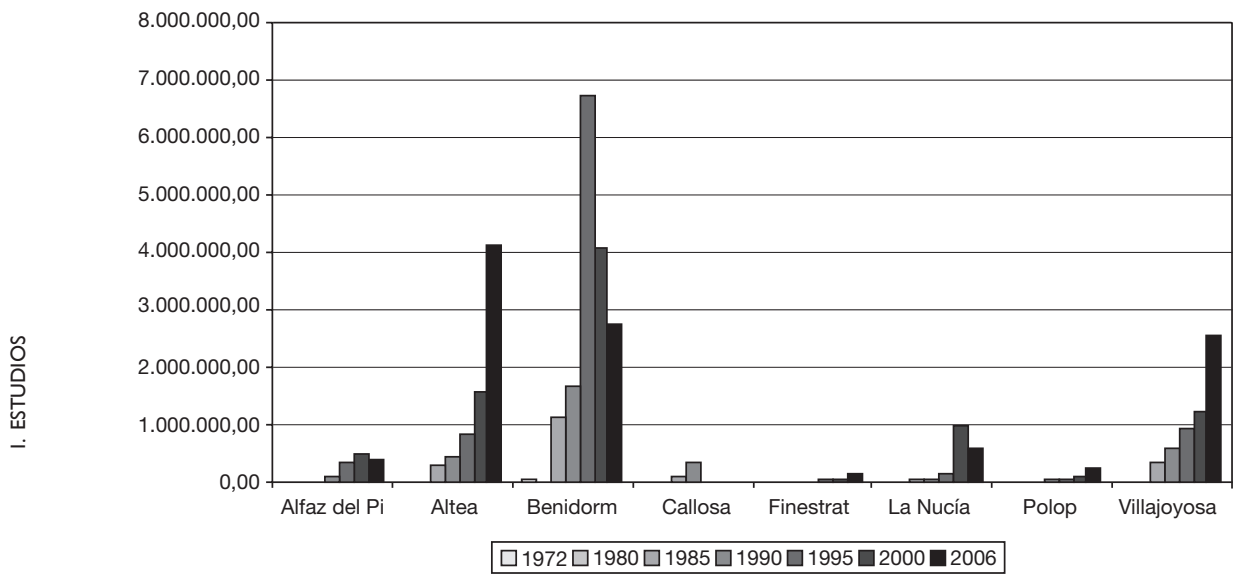

128 Fuente: Elaboración propia a partir de las actas del CAMB.

Revista de Estudios de la Administración Local y Autonómica 
Vemos que el principal deudor, es también el que mayores aportaciones debe realizar anualmente, Benidorm. Lo relevante del tema es cómo una entidad con el nivel de deuda que hemos comentado, funciona. La característica del servicio que presta, la garantía que supone su existencia, y la confianza mutua que generalmente existe entre sus miembros, permiten esta situación que de otra forma sería inconcebible, además de económicamente insostenible, para una empresa privada. Los municipios utilizan los recursos presupuestados correspondientes a las aportaciones anuales al CAMB como cantidades adicionales que entran a formar parte de los recursos municipales, mientras estas cantidades no se ingresen al CAMB. Incluso aquellos municipios en donde el servicio de abastecimiento es gestionado directamente por ellos, perciben los ingresos por las facturas del agua en baja como recursos extraordinarios municipales ${ }^{28}$, es decir, los ayuntamientos disponen de un crédito que puede ser considerado como temporal, que cubrirá con las aportaciones del periodo de facturación siguiente, y que además, no tiene gastos financieros, al menos de momento.

\section{v. CONCLUSIONES}

En este trabajo hemos destacado la importancia que una adecuada identificación de las instituciones competentes tiene en la gestión de los recursos hídricos. Lo determinante del análisis institucional en temas de gestión de agua ha quedado patente en los últimos años, tanto a nivel internacional como a escala local, tal y como ha quedado patente en el IV Foro Mundial del Agua y, algunos años antes, con el establecimiento de los Principios de Dublín. En nuestro caso concreto, hemos demostrado como la toma de decisiones al nivel más bajo posible facilita la participación de los agentes implicados de forma más directa y aporta el conocimiento previo de unas reglas de funcionamiento particulares y específicas de la zona.

La irregularidad en la disponibilidad de recursos y la dualidad existente entre la demanda procedente de un sector agrícola rentable y una demanda urbano-turística centrada en el polo de Benidorm desde los años setenta, hacen de la comarca de la Marina Baja un modelo apropiado para el análisis de prácticas de gestión integrada de recursos hídricos. La clave del éxito de esta gestión se basa en el funcionamiento de un ente de ámbito comarcal en donde confluyen los intereses de todos los agentes implicados; siendo el Consorcio de Aguas de la Marina Baja es el organismo encargado de la distribución del agua en alta para la comarca.

Su funcionamiento económico-presupuestario depende del mantenimiento de un equilibrio entre ingresos y gastos en ocasiones difícil de conseguir debido a la debilidad y conflictividad del funcionamiento de estos entes formados por la participación de Administraciones Públicas de distinto nivel. La distribución entre gastos fijos

28 En los municipios donde la gestión es indirecta, Aquagest ingresa directamente al CAMB la parte correspondiente a la recaudación por la facturación del agua en baja, correspondiendo al ayuntamiento el ingreso de la cuota que le corresponde. 
y variables que corresponde a cada uno de los municipios consorciados depende del porcentaje de participación según los estatutos en el caso de los primeros, y del consumo de agua del año inmediatamente anterior para el caso de los gastos variables. Pese a las desviaciones reales de la situación actual de los municipios con respecto a la reflejada en los estatutos de 1977, los municipios han evitado cualquier modificación tendente a adecuar ambos escenarios por temor a perder peso político dentro del ente, aunque eso suponga mayores costes fijos.

En el dilatado periodo de vida del CAMB este ente ha pasado por momentos críticos, tanto institucionales como económico financieros. Institucionalmente, ante la falta de consenso entre las partes, se continúa funcionando con unos Estatutos de 1977 que han quedado obsoletos, tanto por la nueva articulación de la España de las Autonomías -obsérvese que la Generalitat Valenciana no forma parte del mismo-, como por los cambios de participación de los Ayuntamientos en la contribución a su financiación. Desde el punto de vista económico financiero, la falta de aportaciones continuadas de algunos ayuntamientos ha generado momentos de crisis institucional que han estado a punto, en varias ocasiones, de provocar la falta de operatividad del mismo.

Sin embargo, transcurridos más de 30 años desde su puesta en marcha, las ventajas que su existencia ha reportado deben de considerarse más relevantes que los problemas institucionales y financieros generados, llegando a la actualidad como una pieza clave para la gestión eficiente del agua en la zona donde actúa, siendo un ejemplo adecuado para otras zonas con problemas semejantes.

\section{REFERENCIAS BIBLIOGRÁFICAS}

AEAS (2004), Suministro de Agua Potable y Saneamiento en España (2004) XI Encuesta Nacional. Madrid: Asociación Española de Abastecimiento de Agua y Saneamiento. Aguilera-Klink, F.; Sánchez-García, J. (2005), Water markets in Tenerife: the Conflicts between Instrumental and Ceremonial Functions of the Institutions International Journal of Water, 3.2, 166-185

Bromley, D. (1989), Economic Interest and Institutions, New York: Basil Blackwell.

CAMB (2005), Aprovechamiento Integral de los Recursos de la zona de la Marina Baja Francisco Santiago Andrés, Ingeniero Director del CAMB. Jornadas sobre las Desaladoras, Orihuela: Escuela Politécnica Superior de Orihuela. Abril 2005.

CAMB (2006), Memoria del Consorcio para Abastecimiento y Saneamiento de la Marina Baja. CAMB, Callosa d'En Sarriá.

CAMB (2007), Informe Anual 2006. Consorcio de Aguas de la Marina Baja. Callosa d'En Sarriá.

Castro, J.E., Torregrosa, M.L.; Allen, A.; Gómez-González, R.; Vera, J.; Kloster, K. (2006), «Borrador del documento base de la perspectiva transversal B; DesarroIlo institucional y procesos políticos» En preparación para el IV Foro Mundial del 130 Agua. 
CHJ (1999), Plan Hidrológico de la cuenca del Júcar. Ministerio de Medio Ambiente. Valencia: Confederación Hidrográfica del Júcar.

Eraso, A. (2006) «Tarificación ambiental del agua en el País Vasco». Convención Hidronómica. Agencia Catalana del Agua. Barcelona.

Erruz, J. (1997) «Reasignaciones, concesiones sucesivas y aprovechamientos compartidos; (tres casos de comunidades de usuarios que optaron por romper las rigideces de las actuales concesiones finalistas)». En J. López-Gálvez y J.M. Naredo, La gestión del agua de riego. Colección Economía y Naturaleza. Fundación Argentaria, Madrid.

Fernández Pérez, D. (2002), Los ocho mil monopolios del agua urbana, Revista de Obras Públicas, extraordinario de octubre, n. ${ }^{\circ}$ 3, 425, pp. 93-102.

García-Serra, J.; Cabrera, E. (1998), Problemática de los abastecimientos urbanos en España. Propuesta de urgentes soluciones. I Congreso Ibérico Sobre Gestión y Planificación Aguas. El Agua a debate desde la Universidad. Por una Nueva Cultura del Agua. Zaragoza, 14-18 de Septiembre.

Hall, D. (2005) «Introducción», en Varios Autores, Por un modelo público de agua: triunfos, luchas y sueños, Transnational Institute \& Corporate European Observatory, Traducción de Beatriz Martínez, Ed. El Viejo Topo.

Hovik, S.; Reitan, M. (2004), National Environmental Goals in Search of Local Institutions, Environment and Planning C: Government and Policy, Vol. 22. pp 687-99.

IGAE (2008) Sector Público Empresarial y Fundacional. Composición y Estructura, 2006. Intervención General de la Administración del Estado IGAE, Madrid: Ministerio de Economía y Hacienda.

Johansson, R.C. (2000) Pricing Irrigation Water. A literature Survey. Policy Research Working Paper 2449. Rural Development Department. The World Bank.

Martín Mateo, R. (1992) Los consorcios locales. Una institución en auge. Revista de la Administración Pública, n. ${ }^{\circ}$ 129, pp. 7-18.

Martin Mateo, R. (1987) Entes Locales Complejos: mancomunidades, agrupaciones, consorcios, comarcas, áreas metropolitanas Madrid: Ed. Trivium

MIMAM, (2000) Libro Blanco del Agua en España. Madrid: Ministerio de Medio Ambiente.

Mishan, E. J.(1967) The Costs of Economic Growth. Londres: Staples Press.

North, D. C. (1993), Instituciones, cambio institucional y desempeño económico. México: Fondo de Cultura Económica.

Orduña Rebollo, E. (2005) «Otros Entes Locales complejos: Los Consorcios». Carta Local, Revista de la Federación Española de Municipios y Provincias, N. ${ }^{\circ}$ 167, p. 44. Febrero de 2005.

Ostrom, E. (2000), El gobierno de los bienes comunes: La evolución de las instituciones de acción colectiva, México: UNAM-CRIM-FCE.

Polany, K. (1976), La economía como actividad institucionalizada, en Polanyi K., Arensberg M. y Pearson H. Comercio y mercado en los imperios antiguos, pp. 289-316. Barcelona: Labor.

Presidencia del Gobierno (1967a), Recursos Hidráulicos: II Plan de Desarrollo Económico y Social, 1968-19741. Comisaría del Plan de Desarrollo Económico y Social. Madrid: Imprenta Nacional BOE. 
Presidencia del Gobierno (1967b), Estructura y Servicios Urbanos: Il Plan de Desarrollo Económico y Social, 1968-19741. Comisaría del Plan de Desarrollo Económico y Social. Madrid: Imprenta Nacional BOE.

Rodríguez, F.; Menéndez, R.; Cadenas, A. (2005) «Comarcas, consorcios y otras experiencias innovadoras de cooperación territorial en España», Boletín de la A.G.E., n. ${ }^{\circ}$ 39, pp. 177-199.

Saleth, M.; Dinar, A. (1999), Evaluating Water Institutions and Water Sector Performance. Washington D.C: World Bank Technical Paper No. 447.

Sosa Wagner, F. (2008) La Gestión de los Servicios Públicos Locales. Pamplona: Ed. Thomson-Civitas. ARANZADI.

Torregrosa, T. (2008) «El modelo socioeconómico de gestión de los recursos hídricos en la comarca de la Marina Baja (Alicante). Un enfoque de Gestión Integrada de Recursos Hídricos». Tesis Doctoral. Departamento de Análisis Económico Aplicado. Universidad de Alicante.

Torregrosa, T. (2005), Use competition an d water exchange in Marina Baja district, Alicante, Spain, Water Science and Technology: Water Supply, Vol.5; Issue 3-4.

Torregrosa, T., McIntosh, B.S.; Jeffrey, P. (2006) Institutional perspectives on the value and valuation of water. IWA World Water Congress and Exhibition. 10 - 14 September 2006 Beijing China. 